Marquette University

e-Publications@Marquette

Economics Faculty Research and Publications

Economics, Department of

$11-1-1988$

\title{
Money Demand and the Effects of Fiscal Policies: A Comment
}

Farrokh Nourzad

Marquette University, farrokh.nourzad@marquette.edu

James McGibany

Marquette University, james.mcgibany@marquette.edu

Published version. Journal of Money, Credit, and Banking, Vol. 20, No.4 (November 1988): 706-714. DOI. (C) 1988 Ohio State University Press. Used with permission. 


\section{Money Demand and the Effects of Fiscal Policies}

\section{A Comment by James M. McGibany and Farrokh Nourzad}

In a recent article, Mankiw and Summers (1986) examined the explanatory and predictive power of the demand functions for M1 and M2 under alternative specifications of the scale variable that enters these functions. They found that for the M1 function consumer spending outperformed GNP, whereas for M2 disposable income and final sales generated the best results. The replacement of GNP in money demand with consumption spending or disposable income has an interesting implication for the effect of tax policies.

More than a decade ago, Holmes and Smyth (1972) showed that the sign of the tax multiplier is ambiguous when money demand depends on income taxes either through consumption or disposable income. To our knowledge, Mankiw and Summers are the first to provide empirical insight into this issue. They found that when consumer spending is used as the scale variable in money demand, a necessary and sufficient condition for the tax multiplier to be positive is satisfied. In reaching this conclusion, Mankiw and Summers used a partial equilibrium approach in that they estimated only the money market parameters needed to evaluate this condition. As a result, they had to turn to previous literature for estimates of product market parameters that also enter this condition.

In this paper, we take a more general approach to the problem of determining the sign of the tax multiplier when money demand depends on income taxes. Based on a simultaneous-equations model, we estimate the income tax multiplier using three alternative scale variables in the money demand function: GNP, consumption of nondurables and services, and disposable income. Our findings indicate that the tax multiplier remains negative when GNP is replaced with either of the latter two variables, but it becomes smaller in absolute value.

The authors thank two anonymous referees of the Journal for their helpful comments. Financial support for this research was provided by the College of Business Administration, Marquette University, through a fellowship from the Miles Fund.

JAMES M. MCGIBANY is assistant professor and FARROKH NouRZAD is associate professor of economics, Marquette University.

Journal of Money, Credit, and Banking, Vol. 20, No. 4 (November 1988)

Copyright $\odot 1988$ by the Ohio State University Press 


\section{THEORETICAL BACKGROUND}

In this section we specify two multiequation macro models that are different only with respect to the scale variable that enters the money demand function, and derive their tax multipliers. The first model, which incorporates major features of standard textbook models, uses GNP as the scale variable in money demand, and gives rise to an unambiguously negative tax multiplier. This model will serve as the benchmark for our subsequent analysis. The second model retains all features of the first but uses consumption of nondurables and services in money demand. The tax multiplier of this model is sign-indeterminate because of the opposing effects of tax policies in the money and product markets.

\section{Model I: GNP as the Scale Variable in Money Demand-Benchmark}

Let $Y$ denote income, $Y d$ disposable income, and $r$ the rate of interest. The product market is represented by equations (1)-(12) below:

$$
\begin{array}{ll}
C_{1}=C_{1}(Y d) & \text { Consumption of nondurables and services } \\
C_{2}=C_{2}(Y d, r) & \text { Consumption of durables } \\
C=C_{1}+C_{2} & \text { Consumption identity } \\
Y d=Y+T R-T & \text { Disposable income identity } \\
T R=T R_{0} & \text { Transfer payments to persons } \\
T=T(Y) & \text { Income taxes } \\
I_{1}=I_{1}(Y, r) & \text { Fixed business investment } \\
I_{2}=I_{20} & \text { Inventory investment } \\
I=I_{1}+I_{2} & \text { Investment identity } \\
G=G_{0} & \text { Government expenditures } \\
X=X_{0} & \text { Net exports } \\
Y=C+I+G+X & \text { Income identity }
\end{array}
$$

The money market is represented by equations (13)-(15):

$$
\begin{array}{ll}
L=L(Y, r) & \text { Money demand } \\
M=M_{0} & \text { Money supply } \\
L=M & \text { Money identity }
\end{array}
$$


We make the standard assumptions that $0<C_{Y d}<1, C_{r}<0,0<T_{y}<1$, $I_{y}>0, I_{r}<0, L_{y}>0$, and $L_{r}<0$.

The tax multiplier for this model is given by

$$
d Y / d T_{0}=\frac{-\left(C_{1 Y d}+C_{2 Y d}\right)}{1-\left(1-T_{y}\right)\left(C_{1 Y d}+C_{2 Y d}\right)+\left(C_{2 r}+I_{1 r}\right)\left(L_{Y} / L_{r}\right)-I_{1 Y}}
$$

which is unambiguously negative under the stated assumptions, and the condition required for stability of an equilibrium of the model.

\section{Model II: Consumption of Nondurables and Services as the Scale Variable}

All equations will remain the same as benchmark except money demand, (13), which is replaced by

$$
L=L\left(C_{1}, r\right), \text { where } L_{C 1}>0 .
$$

The tax multiplier for this model is given by

$$
d Y / d T_{0}=\frac{-\left(C_{1 Y d}+C_{2 Y d}\right)+\left(C_{2 r}+I_{1 r}\right)\left(L_{C 1} / L_{r}\right)\left(C_{1 Y d}\right)}{1-\left(1-T_{y}\right)\left[\left(C_{1 Y d}+C_{2 Y d}\right)-\left(C_{2 r}+I_{1 r}\right)\left(L_{C 1} / L_{r}\right)\left(C_{1 Y d}\right)\right]-I_{1 Y}}
$$

which is sign-indeterminate under the assumptions of the model and stability requirement. Note that if one replaces consumer spending with disposable income in Equation (13'), one obtains the same multiplier as (17), given that $L_{Y d}=$ $\left(L_{C 1}\right)\left(C_{1 Y d}\right)$.

Although the sign of the tax multiplier associated with Model II cannot be determined, some inference regarding its magnitude relative to that of the benchmark can be drawn. Under the assumptions of the model, the absolute value of this multiplier is smaller than the benchmark; the expansionary effect of tax cuts in the product market are offset, at least partially, by the contractionary effect caused by the resulting increase in money demand.

\section{EMPIRICAL RESULTS}

In this section we specify empirical counterparts to the equations of the above models and choose a suitable technique for estimating them. For this purpose we employ a variant of a framework used by Chow (1983). The major features of Chow's model are: (1) all equations are linear, and are specified in the first-difference form; (2) the consumption function and the money demand function include the lagged value of the dependent variable as an independent variable; (3) all equations except money demand are specified in real terms; (4) the equations that are in real terms are deflated by introducing the lagged value of the implicit GNP deflator as an independent variable without restricting its coefficient to unity; and (5) income taxes are treated exogenously. 
We modify Chow's framework in a number of ways. First, for well-known econometric reasons, we do not include lagged dependent variables as explanatory variables. Second, we specify all equations in real terms. ${ }^{1}$ Third, we treat taxes endogenously, and in the tax function we include not only an income variable, but also a dummy variable, $D$, indicating major tax policy changes in the United States. These are the 1964 Kennedy tax cut, the 1968 Johnson tax surcharge, the 1975 Ford tax rebate, and the 1981-83 Reagan tax cuts. ${ }^{2}$

Recently, McGibany and Nourzad (1986) found that interest rate volatility exerts a significant effect on money demand, especially when the sample period is extended beyond the third quarter of 1979. Because our sample period runs through 1985, we include lagged values of a measure of volatility of interest rates, $V_{t-1}$ and $V_{t-2}$, in all money demand functions. Our measure of interest rate volatility is a twenty-fourmonth moving average standard deviation of the first difference of the log of the measure of the rate of interest used in our subsequent empirical analysis. In specifying our empirical fixed business investment demand, following Chow (1983) we include not only the first difference of income and the rate of interest, but also the lagged value of the levels of income, $Y_{t-1}$, and investment, $I_{1, t-1}$, in addition to the lagged value of the rate of interest, $r_{t-1}$.

We are now in a position to briefly discuss the approach we use to estimate our models. Either of the models represents a system of five structural equations $(1,2,6$, 7 , and either 13 or $\left.13^{\prime}\right)$, five identities, six endogenous variables $\left(C_{1}, C_{2}, T, I_{1}, Y\right.$, and $r$ ), and twelve exogenous variables $\left(T R_{0}, G_{0}, X_{0}, I_{20}, M_{0}, D, V_{t-1}, V_{t-2}, I_{1, t-1}\right.$, $Y_{t-1}, r_{t-1}$, and $\left.Y d_{t-1}\right){ }^{3}$ Since each model represents a simultaneous-equations system, it lends itself to two-stage-least-squares estimation. In the first stage, the reduced-form equation for $\Delta Y$, which is common to both models, will be estimated. Using the predicted values from this equation, taxes and the inverse money demand function (the rate of interest) will then be estimated. Using the predicted values of these variables, consumption of nondurables and services, consumption of durables, and fixed business investment will be estimated in the second stage.

The final step that has to be taken prior to estimation is to quantify the arguments of the equations of the models. In order to capture the effect of tax policies over a year, we specify all first differences from end of the year to end of the year using quarterly data at annualized rates covering the years 1948 through $1985 .{ }^{4}$ Taxes are taken to be the sum of federal, state, and local personal income taxes, and social

\footnotetext{
${ }^{1}$ In the case of policy variables (income taxes, government expenditures, and money supply) for which data in constant dollars are not available, the implicit GNP deflator is used for conversion to real values.

${ }^{2}$ This dummy variable is constructed as follows. In the quarter when a major tax cut or rebate is implemented, $D$ takes the value of -1 , while in any quarter where there is a tax increase, $D$ takes the value of 1 . Similarly, in the quarter when tax cuts or rebates expire, $D$ takes the value of 1 , and in the quarter when tax increases expire, $D$ takes the value of -1 . In all other quarters, $D$ takes the value of 0 . Because of this construction, the expected sign of $D$ in the tax function is positive.

${ }^{3}$ In order to capture the lagged effects of fiscal and monetary policies, and to improve the explanatory power of the reduced-form equation for $\Delta Y$, the lagged values of $\Delta M$ and $\Delta G$ will also be included in this equation.

${ }^{4}$ We also estimated the model using annual data and obtained results which were virtually identical to those reported below. The use of quarterly data enables us to estimate not only the within-the-year impact of tax policies but also the within-the-quarter effect of these policies.
} 


\section{TABLE 1}

Estimated Coefficients of the STRuctural Equations of Model I: GNP AS THE SCALE VARIAble IN MONey Demand 1948-1985 ( $t$-ratios in parentheses)

\begin{tabular}{|c|c|c|c|c|c|}
\hline & $\Delta T$ & $\Delta C_{1}$ & $\Delta R$ & $\Delta C_{2}$ & $\Delta I_{1}$ \\
\hline Const. & $\begin{array}{c}5.63 \\
(1.58)\end{array}$ & $\begin{array}{l}10.71 \\
(1.35)\end{array}$ & $\begin{array}{c}0.23 \\
(0.70)\end{array}$ & $\begin{array}{c}-5.25 \\
(-0.78)\end{array}$ & $\begin{array}{l}-60.52 \\
(-3.19)\end{array}$ \\
\hline$\Delta \hat{Y}_{t}$ & $\begin{array}{c}0.13 \\
(3.33)\end{array}$ & & $\begin{array}{c}0.005 \\
(2.26)\end{array}$ & & $\begin{array}{c}0.33 \\
(7.36)\end{array}$ \\
\hline$\Delta Y \hat{d}_{t}$ & & $\begin{array}{c}0.28 \\
(5.63)\end{array}$ & & $\begin{array}{c}0.17 \\
(4.02)\end{array}$ & \\
\hline$Y d_{t-1}$ & & $\begin{array}{c}0.004 \\
(1.20)\end{array}$ & & $\begin{array}{c}0.002 \\
(0.54)\end{array}$ & \\
\hline$\Delta \hat{R}_{t}$ & & & & $\begin{array}{c}-6.75 \\
(-4.27)\end{array}$ & $\begin{array}{c}-7.29 \\
(-1.65)\end{array}$ \\
\hline$D$ & $\begin{array}{l}18.40 \\
(2.60)\end{array}$ & & & & \\
\hline$\Delta M_{t}$ & & & $\begin{array}{c}-0.05 \\
(-3.92)\end{array}$ & & \\
\hline$V_{t-1}$ & & & $\begin{array}{l}0.003 \\
(0.79)\end{array}$ & & \\
\hline$V_{t-2}$ & & & $\begin{array}{l}-0.005 \\
(-1.49)\end{array}$ & & \\
\hline$I_{1, t-1}$ & & & & & $\begin{array}{c}-0.61 \\
(-3.93)\end{array}$ \\
\hline$Y_{t-1}$ & & & & & $\begin{array}{c}0.14 \\
(3.63)\end{array}$ \\
\hline$R_{t-1}$ & & & & & $\begin{array}{c}-6.35 \\
(-1.81) \\
\end{array}$ \\
\hline $\bar{R}^{2}$ & 0.34 & 0.53 & 0.38 & 0.40 & 0.75 \\
\hline$F$ & 9.61 & 20.12 & 5.44 & 8.33 & 26.40 \\
\hline RHO & & & & & $\begin{array}{c}0.38 \\
(2.44)\end{array}$ \\
\hline D-W & 2.00 & 2.05 & 1.86 & 2.12 & 2.01 \\
\hline
\end{tabular}

NOTES: The symbol ^ indicates that the corresponding variable is an instrument.

First differences are fourth quarter to fourth quarter using quarterly data at annualized rates.

security taxes. ${ }^{5}$ Our measure of the rate of interest is Moody's AAA bond yield. ${ }^{6} \mathrm{M} 1$ is used as our measure of the money stock. All other measures are as defined in the previous section. ${ }^{7}$

The estimation results for Models I and II are presented in Tables 1 and 2, respectively. Note that, while Table 1 includes estimates of all five structural equations, Table 2 includes only estimates of the inverse money demand function, consumption of durables, and fixed business investment. This is because the tax function and the consumption of nondurables and services are common to both

\footnotetext{
${ }^{5}$ We tried several combinations of these tax revenues as the measure of taxes, and in all cases the results were generally consistent with those reported below.

${ }^{6}$ Ideally, the interest rate entering money demand should be a short-term rate, and that entering investment a long-term rate. The two could then be related through a term structure equation. We avoided this complication in our analysis.

${ }^{7}$ All data used here are taken from the Citibase data tape, Citibank, N.A.
} 


\section{TABLE 2}

ESTIMATED COEFFICIENTS OF THE STRUCTURAL EQUATIONS OF MODEL II:

Consumption of Nondurables and Services as the Scale Variable in Money Demand

1948-1985 ( $t$-ratios in parentheses)

\begin{tabular}{|c|c|c|c|}
\hline & $\Delta R$ & $\Delta C_{2}$ & $\Delta I_{1}$ \\
\hline Const. & $\begin{array}{c}-0.14 \\
(-0.31)\end{array}$ & $\begin{array}{c}-6.64 \\
(-1.01)\end{array}$ & $\begin{array}{l}-60.76 \\
(-3.34)\end{array}$ \\
\hline$\Delta \hat{Y}_{t}$ & & & $\begin{array}{c}0.33 \\
(7.26)\end{array}$ \\
\hline$\Delta Y \hat{d}_{t}$ & & $\begin{array}{c}0.16 \\
(3.95)\end{array}$ & \\
\hline$Y d_{t-1}$ & & $\begin{array}{l}0.002 \\
(0.82)\end{array}$ & \\
\hline$\Delta \hat{C}_{1 t}$ & $\begin{array}{c}0.02 \\
(2.15)\end{array}$ & & \\
\hline$\Delta \hat{R}_{t}$ & & $\begin{array}{c}-7.06 \\
(-2.19)\end{array}$ & $\begin{array}{l}-9.59 \\
(-2.11)\end{array}$ \\
\hline$\Delta M_{t}$ & $\begin{array}{c}-0.04 \\
(-3.84)\end{array}$ & & \\
\hline$V_{t-1}$ & $\begin{array}{c}0.002 \\
(0.57)\end{array}$ & & \\
\hline$V_{t-2}$ & $\begin{array}{l}-0.005 \\
(-1.43)\end{array}$ & & \\
\hline$I_{1, t-1}$ & & & $\begin{array}{c}-0.59 \\
(-3.91)\end{array}$ \\
\hline$Y_{t-1}$ & & & $\begin{array}{c}0.14 \\
(3.69)\end{array}$ \\
\hline$R_{t-1}$ & & & $\begin{array}{c}-6.64 \\
(-1.95)\end{array}$ \\
\hline $\bar{R}^{2}$ & 0.37 & 0.40 & 0.76 \\
\hline$F$ & 6.02 & 8.60 & 28.02 \\
\hline RHO & & & $\begin{array}{c}0.34 \\
(2.10)\end{array}$ \\
\hline D-W & 1.90 & 2.12 & 2.02 \\
\hline
\end{tabular}

NOTES: The symbol ^ indicates that the corresponding variable is an instrument.

First differences are fourth quarter to fourth quarter using quarterly data at annualized rates.

models, since they do not depend on the inverse money demand function that differs between the two models.

As is evident from these results, our simple models perform reasonably well; all parameter estimates have the expected signs and most are significant at the 5 percent level or better. This gives us confidence to use these estimates to calculate the tax multiplier associated with each model. For Model I (benchmark), a value of -1.29 is obtained. For Model II with consumption of nondurables and services, $C_{1}$, as the scale variable in money demand, we obtain a value of -0.94 . These results suggest that the use of consumption spending in money demand does not change the conclusion from standard models that the tax multiplier is negative. However, they do confirm our a priori theoretical expectation that the multiplier is smaller in absolute value when money demand is influenced by taxes.

An interesting question that arises here is whether or not the above findings 


\section{TABLE 3}

Estimated Coefficients of the Structural Equations of Model II-A: DisPosable Income as the SCALE VARIABle in MONEY DEMAND $1948-1985$ ( $t$-ratios in parentheses)

\begin{tabular}{|c|c|c|c|}
\hline & $\Delta R$ & $\Delta C_{2}$ & $\Delta I_{1}$ \\
\hline Const. & $\begin{array}{c}0.20 \\
(0.57)\end{array}$ & $\begin{array}{c}-5.70 \\
(-0.85)\end{array}$ & $\begin{array}{c}-59.32 \\
(-3.26)\end{array}$ \\
\hline$\Delta \hat{Y}_{t}$ & & & $\begin{array}{c}0.33 \\
(7.32)\end{array}$ \\
\hline$\Delta Y \hat{d}_{t}$ & $\begin{array}{l}0.006 \\
(2.03)\end{array}$ & $\begin{array}{c}0.16 \\
(3.96)\end{array}$ & \\
\hline$Y d_{t-1}$ & & $\begin{array}{c}0.002 \\
(0.65)\end{array}$ & \\
\hline$\Delta \hat{R}_{t}$ & & $\begin{array}{c}-6.97 \\
(-2.12)\end{array}$ & $\begin{array}{c}-9.31 \\
(-2.06)\end{array}$ \\
\hline$\Delta M_{t}$ & $\begin{array}{c}-0.04 \\
(-3.76)\end{array}$ & & \\
\hline$V_{t-1}$ & $\begin{array}{c}0.002 \\
(0.65)\end{array}$ & & \\
\hline$V_{t-2}$ & $\begin{array}{l}-0.005 \\
(-1.36)\end{array}$ & & \\
\hline$I_{1, t-1}$ & & & $\begin{array}{c}-0.59 \\
(-3.92)\end{array}$ \\
\hline$Y_{t-1}$ & & & $\begin{array}{c}0.14 \\
(3.67)\end{array}$ \\
\hline$R_{t-1}$ & & & $\begin{array}{c}-6.49 \\
(-1.91)\end{array}$ \\
\hline $\bar{R}^{2}$ & 0.36 & 0.40 & 0.76 \\
\hline$F$ & 5.83 & 8.44 & 27.48 \\
\hline RHO & & & $\begin{array}{c}0.35 \\
(2.18)\end{array}$ \\
\hline D-W & 1.87 & 2.11 & 2.02 \\
\hline
\end{tabular}

NOTES: The symbol ^ indicates that the corresponding variable is an instrument.

First differences are fourth quarter to fourth quarter using quarterly data at annualized rates.

would hold if disposable income were used as the scale variable in money demand. Recall from the previous section that, in theory, the tax multiplier is invariant with respect to the use of consumption or disposable income in money demand. This equivalence requires that $L_{Y d}=\left(L_{C 1}\right)\left(C_{1 Y d}\right)$, and presumes that all other parameters entering the multiplier remain the same upon the replacement of consumption with disposable income. In order to see if these conditions are satisfied in our sample, we reestimated a version of Model II which incorporates disposable income in money demand. ${ }^{8}$ The results are presented in Table 3.

Once again, all parameter estimates have the correct sign, and most are significant at least at the 5 percent level. A comparison of these results with those reported in Table 2 reveals that the estimated values of the parameters that are common between the two models are virtually identical. Further, we find that $L_{Y d}$ is nearly

\footnotetext{
${ }^{8}$ In reestimating Model II, we chose not to impose any restrictions on the parameters of the model.
} 
equal to $\left(L_{C 1}\right)\left(C_{1 Y d}\right): 0.006$ versus $0.0056 .{ }^{9}$ These results suggest that the tax multiplier associated with Model II-A should be comparable to that of Model II. In fact, using the estimates from Table 3, we obtain a multiplier of -0.92 (versus -0.94 from Model II). ${ }^{10}$ This finding is particularly reassuring; the empirical models estimated without constraints satisfy an a priori restriction imposed on their parameters by the theoretical model under which the two models generate the same results.

\section{CONCLUSIONS}

In this paper we have found that tax cuts are expansionary whether or not one replaces GNP with consumption of nondurables and services or disposable income as the scale variable in the money demand functions. However, when taxes enter the demand for money through either of the latter two scale variables, the expansionary effect of tax cuts is diminished. While our finding regarding the effect of income taxes on money demand is in general conformity with that of Mankiw and Summers, the two studies lead to opposite results with respect to the output effect of tax policies. This conflict is attributable to the different approaches used by the two studies.

Mankiw and Summers estimate a money demand function in which consumer spending is the scale variable, and find evidence that the tax multiplier may be positive. The partial equilibrium nature of their approach forced them to borrow other parameter estimates needed to arrive at this conclusion from previous literature which used different sample periods and methodologies, among other things. It is perhaps because of this fact that Mankiw and Summers (1986, pp. 427-28) caution that "the uncertainty [regarding their calculations] is necessarily large," and that the tax multiplier is "probably" positive. In fact, they suggest that "it would be valuable to embed a money demand function with consumption as a scale variable in a large Keynesian macroeconometric model and then to examine its properties. This experiment would refine the highly stylized calculations presented [in their paper]."

Except for the scale of the model, their suggestion is precisely what we have attempted to implement. We have arrived at our conclusions using a small macroeconometric model which has its theoretical roots in the basic Keynesian general equilibrium framework. This has been accomplished by treating taxes endogenously, incorporating the foreign sector, and estimating the resulting model simultaneously. These differences are sufficient to account for the opposite conclusions reached by Mankiw and Summers and those reported here. However, in view of the simplicity of our model, the results should be taken as preliminary. This, together with the conflict between our findings and those of Mankiw and Summers, suggests that more research is needed before the issue of the output effect of tax policies is satisfactorily resolved.

\footnotetext{
${ }^{9}$ Because we estimate inverse money demand functions, in order to obtain the implied estimators of $L_{C 1}$ and $L_{Y d}$ from Tables 2 and 3, one must divide $R_{C 1}$ and $R_{Y d}$ by the corresponding $-R_{M}$.

${ }^{10}$ The finding that the tax multiplier remains negative but becomes smaller in absolute value when
} 


\section{LITERATURE CITED}

Chow, Gregory C. Econometrics. New York: McGraw-Hill, 1983.

Holmes, James M., and David J. Smyth. "The Specification of the Demand for Money and the Tax Multiplier." Journal of Political Economy 80 (January/February 1972), 179-85.

$\rightarrow$ Mankiw, N. Gregory, and Lawrence H. Summers. "Money Demand and the Effects of Fiscal Policies." Journal of Money, Credit, and Banking 18 (November 1986), 415-29.

McGibany, James M., and Farrokh Nourzad. "Interest Rate Volatility and the Demand for Money." The Quarterly Review of Economics and Business 26 (Autumn 1986), 73-83.

GNP is replaced with either consumption or disposable income in money demand also holds when first differences are taken to represent changes from quarter to quarter, rather than end of the year to end of the year. However, the difference between the within-the-quarter multipliers estimated from Models II and II-A is not as small as that of the within-the-year multipliers reported above. 